\title{
Therapeutic strategies in pneumonia: going beyond antibiotics
}

\author{
Holger Müller-Redetzky, Jasmin Lienau, Norbert Suttorp and \\ Martin Witzenrath
} Affiliation: Dept of Infectious Diseases and Pulmonary Medicine, Charité - Universitätsmedizin Berlin, Berlin,
Germany.

Correspondence: Martin Witzenrath, Dept of Infectious Diseases and Pulmonary Medicine, Charité Universitätsmedizin Berlin, Charitéplatz 1, 10117 Berlin, Germany. E-mail: martin.witzenrathAacharite.de

ABSTRACT Dysregulation of the innate immune system drives lung injury and its systemic sequelae due to breakdown of vascular barrier function, harmful hyperinflammation and microcirculatory failure, which contribute to the unfavourable outcome of patients with severe pneumonia. A variety of promising therapeutic targets have been identified and numerous innovative therapeutic approaches demonstrated to improve lung injury in experimental preclinical studies. However, at present specific preventive or curative strategies for the treatment of lung failure in pneumonia in addition to antibiotics are still missing. The aim of this mini-review is to give a short overview of some, but not all, adjuvant therapeutic strategies for pneumonia and its most important complications, sepsis and acute respiratory distress syndrome, and briefly discuss future perspectives.

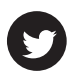

$@$ ERSpublications

A review of preclinical and clinical research on adjuvant therapies for pneumonia http://ow.ly/OeiN3

\section{Introduction}

Pneumonia is the most frequent infectious disease worldwide, causing a tremendous socioeconomic burden in industrialised countries [1]. In addition, pneumonia is the leading infectious cause of death in children worldwide, accounting for $15 \%$ of all deaths of children under the age of 5 years [2]. Concerns arise from the increasing frequency of antibiotic-resistant bacteria and new emerging contagious and deadly pathogens $[3,4]$. Importantly, despite appropriate antibiotic treatment $14-35 \%$ of all hospitalised community-acquired pneumonia (CAP) patients die, depending on age and comorbidities [5]. Thus, a great medical need for the development of adjuvant therapeutic strategies in addition to antibiotics is evident.

When pathogens enter the lung, a variety of pattern recognition receptors (PRRs) [6] recognise microbial structures (pathogen-associated molecular patterns (PAMPs)) and endogenous molecules released after cell injury (danger-associated molecular patterns (DAMPs)). Cells may be injured by specific pathogen components including toxins, or by inflammatory host effectors. In the alveolar compartment, PRRs are expressed by macrophages, dendritic cells and recruited immune cells as well as by epithelial and endothelial cells. Intracellular signalling cascades triggered by ligand binding of PRRs evoke the production of inflammatory cytokines, interferons and chemokines on transcriptional and post-translational levels [6]. Subsequently, local cells are activated and macrophages and neutrophils recruited, leading to the elimination of pathogens and infected cells. However, ongoing PAMP and DAMP release from dying

Received: April 132015 | Accepted after revision: May 262015

Support statement: This work was funded by the Bundesministerium für Bildung und Forschung (CAPSyS TP2, TP4) and by the Deutsche Forschungsgemeinschaft (SFB-TR84 B1, C3, C6, C7). Funding information for this article has been deposited with FundRef.

Conflict of interest: None declared.

Provenance: Submitted article, peer reviewed.

Copyright CERS 2015. ERR articles are open access and distributed under the terms of the Creative Commons Attribution Non-Commercial Licence 4.0. 


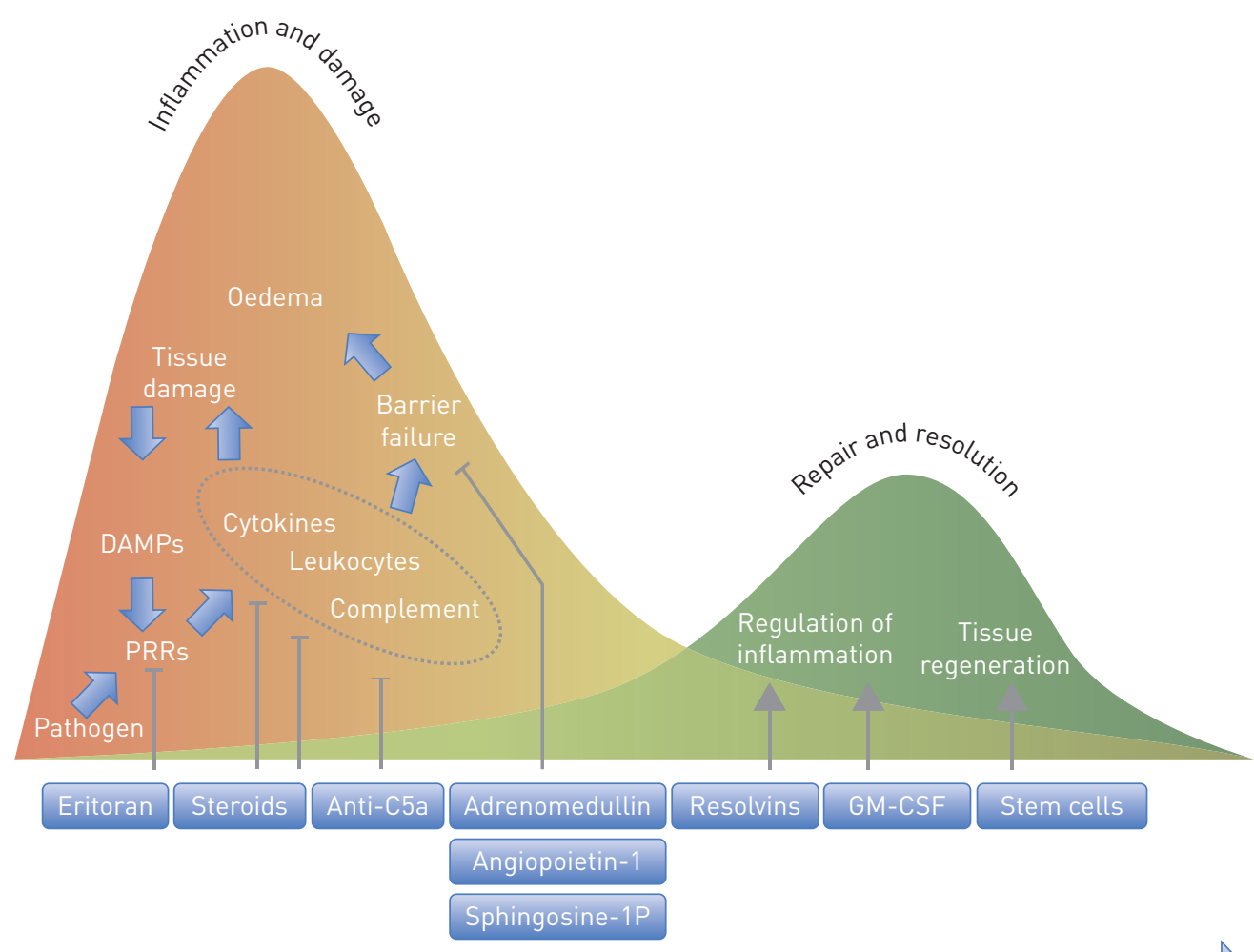

Infection

FIGURE 1 Time course of inflammation, tissue damage and resolution of pneumonia: potential adjuvant therapies. Subsequent to ligand binding pathogen recognition receptors initiate the host inflammatory response, including cytokine production, recruitment of leukocytes and activation of the complement system, thereby leading to elimination of the pathogen and infected cells. However, immune overactivation may lead to tissue damage and barrier failure. From the beginning of the inflammatory response, pulmonary repair and resolution processes are initiated to balance damage and healing of the tissue, ideally resulting in restoration of the original condition (restitutio ad integrum). Potential adjuvant therapies target different processes during pneumonia, thereby potentially exerting beneficial functions in addition to antibiotic treatment. DAMPs: danger-associated molecular patterns; PRRs: pattern recognition receptors; GM-CSF: granulocyte-macrophage colony-stimulating factor.

bacteria and injured cells may evoke immune overactivation with hyperproduction of cytokines, chemokines and lipid mediators, uncontrolled leukocyte recruitment and activation, inadequate activation of complement and coagulation cascades and eventually pulmonary endothelial barrier disruption (fig. 1). Increased permeability results in protein-rich fluid extravasation, lung oedema and acute respiratory distress syndrome (ARDS) (reviewed in [7]), associated with mortality rates ranging from 27 to $45 \%$ [8]. In ARDS patients, mechanical ventilation may further promote the inflammatory response, thereby increasing endothelial barrier disruption [9]. At present, only low tidal volume ventilation is a broadly accepted strategy to reduce mortality in ARDS [10]. Positive end-expiratory pressure (PEEP) also improves ARDS outcome, but how to set the "best" PEEP is still a matter of debate $[11,12]$. Furthermore, early extended prone positioning and early muscle relaxation may reduce mortality in severe ARDS [13-16].

In pneumonia, specific preventive or curative strategies for the treatment of lung failure in addition to antibiotics are not established, but highly required. This mini-review highlights some preclinical and early clinical evidence for successful modulation of the inflammatory response or improvement of pulmonary barrier function in pneumonia and its most important complications, sepsis and ARDS. Space restrictions preclude discussion of all important strategies.

\section{Immunomodulatory strategies in pneumonia Corticosteroids}

The use of corticosteroids in the context of pneumonia has been clinically studied over the past decade with conflicting results. In 2012, NiE et al. [17] published a meta-analysis of nine randomised controlled trials (RCTs) published between 1952 and 2011 with 1001 patients overall. Patient characteristics and 
corticosteroid dosages were rather heterogeneous, and five of the nine trials included were single-centred. Interestingly, a significant reduction of mortality by adjuvant corticosteroid therapy was reported for patients with severe CAP. However, these results were mainly driven by one single-centre study with only 80 patients [18], while the other studies included reported no considerable improvement in mortality.

Retrospective analyses also suggested improvement of patient outcomes due to corticosteroids [19, 20]. Data from a Japanese registry of mechanically ventilated CAP patients demonstrated reduced mortality in a subgroup of patients with CAP and related shock, which was defined by vasopressor use. However, many important parameters including lactate levels, blood pressure and delivery of rapid fluid support and adequate antibiotics were not reported. Furthermore, the applied corticosteroids differed in dosage and species. Thus, interpretation of these data is difficult.

Recently, an innovative RCT in three Spanish centres included patients with a "proinflammatory phenotype" of CAP defined by a C-reactive protein level $>150 \mathrm{mg} \cdot \mathrm{L}^{-1}[21]$. The study included 61 patients treated with $0.5 \mathrm{mg}$ methylprednisolone twice daily for five consecutive days and 59 patients who received placebo. Early clinical deterioration and late treatment failure were analysed using composite end-points. The authors reported a significant reduction of late treatment failure, which was almost exclusively driven by a reduction of radiographic signs of pneumonia. Although treatment failure indicated by radiographic progression is related to mortality in CAP, development and resolution of pulmonary infiltrates under corticosteroid treatment may not be predictive, as corticosteroids are potent inhibitors of leukocyte recruitment to the site of infection. Thus, whether ongoing infectious processes were masked or resolution and repair improved by steroid treatment is questionable. A further very recent multicentre RCT performed in Switzerland from 2009 until 2014 randomised 802 patients to adjuvant treatment with prednisone or placebo. The investigators found that prednisone treatment shortened the time to clinical stability as defined by guidelines by 1.4 days and reduced the length of hospital stay by 1 day while causing more hyperglycaemia needing insulin treatment. It is tempting to speculate that prednisone may have been masking disease symptoms leading to earlier discharge, and overall the reported effects may not necessarily advocate for prednisone treatment. Nevertheless, this study suggests that steroids can alter the course of CAP [22].

Thus, these studies force us to reconsider the use of corticosteroids in pneumonia. In conclusion, corticosteroids cannot be generally recommended in CAP. Current data suggest that corticosteroids may shorten the course of the disease and are possibly beneficial in severely ill, "hyperinflammatory" patients.

\section{Pattern recognition receptor signalling}

Considerable research efforts have been made to develop strategies targeting PRR signalling. For example, Toll-like receptor (TLR) 4 was shown to contribute to the regulation of vascular permeability [23-27]. Therefore, the development of the synthetic TLR4 antagonist eritoran to suppress TLR4/MD2-mediated signalling was highly promising. In fact, eritoran reduced pulmonary inflammation in experimental animal models [28] and in humans given a bolus lipopolysaccharide (LPS) infusion [29]. While eritoran has not yet been assessed in clinical trials for patients with pneumonia, it was evaluated in a phase II clinical trial in subjects with severe sepsis, and a trend toward a lower mortality rate was observed [30]. However, eritoran did not reduce 28-day mortality of patients with severe sepsis in a multinational phase III trial [31]. Since many PRRs are involved in the recognition of the various DAMPs and PAMPs leading to nuclear factor (NF)- $\mathrm{kB}$-mediated transcription of inflammatory genes, it might be more appropriate to interfere with downstream effectors in the inflammatory cascade instead of targeting a single PRR [31].

\section{Complement inhibitors}

A further approach to downregulate the host's immune response is the use of complement inhibitors. The complement system as part of the innate immune system is involved in host defence and inflammation [32], and it may contribute to hyperinflammation and vascular barrier failure mainly mediated by the complement-activated product C5a. In murine models of acute lung injury and systemic inflammatory responses, neutralising $\mathrm{C} 5 \mathrm{a}$ decreased vascular permeability in the lungs and various other organs [33]. Furthermore, blocking of C5a was shown to be protective against lung and extrapulmonary organ failure in pneumonia-induced sepsis [34].

\section{Granulocyte-macrophage colony-stimulating factor}

The haematopoietic growth factor granulocyte-macrophage colony-stimulating factor (GM-CSF) is produced by different cell types, including epithelial cells and macrophages, and exerts immune regulatory effects depending on the dose, presence of other cytokines and the overall context of the immune response (reviewed in [35]). GM-CSF treatment reversed sepsis-associated immunosuppression and improved clinical courses in sepsis patients [36]. In addition, GM-CSF improves antimicrobial pulmonary host 
defence and was shown to be effective at protecting against lung injury in different experimental models, including influenza virus, Klebsiella pneumoniae and Streptococcus pneumoniae pneumonia [37-40]. In two RCTs, systemic GM-CSF treatment did not distinctly improve outcomes of patients with sepsis-induced ARDS [41, 42]. However, recent data from a rather small and uncontrolled trial demonstrated that inhaled GM-CSF treatment was effective in improving pulmonary host defence, oxygenation and outcome in pneumonia-associated ARDS [43]. Thus, inhalative GM-CSF may represent a promising immunomodulatory agent for the prevention or treatment of lung injury in pneumonia, and further trials are warranted.

\section{Beyond bacterial killing: immunomodulating effects of antibiotics?}

Immunomodulatory properties have been ascribed to macrolides and fluoroquinolones. Macrolides have well-characterised immunomodulatory effects in vitro, with 14- and 15-member macrolides interacting with mitogen-activated protein kinases, thereby dampening NF- $\kappa \mathrm{B}$-mediated inflammatory responses towards various stimuli. In addition, macrolides reduce the production of certain virulence factors such as pneumococcal pneumolysin [44] and interfere with the process of quorum sensing [45]. However, only in the treatment of diffuse panbronchiolitis are macrolides known to substantially improve patient survival [46]. The combination therapy of a $\beta$-lactam and a macrolide is recommended in German and European guidelines for patients with severe CAP and in the American Thoracic Society (ATS) guidelines for hospitalised CAP patients [47-49]. The rationale is: 1) a potential bactericidal synergism; 2) the coverage of atypical pathogens (most importantly Legionella spp.); and 3) a possible immunomodulatory effect. However, these recommendations are mainly based on retrospective analyses, in which primarily patients with severe CAP had improved outcomes under combination therapy with a macrolide [50,51]. Notably, a characterisation of the inflammatory profile was not performed in these studies. A recent meta-analysis reported improved survival with a $\beta$-lactam-macrolide combination compared to $\beta$-lactam monotherapy, but this was not the case when combination therapy was compared to guideline adherent therapy with a fluoroquinolone or when the analysis was restricted to the few RCTs available. Notably, severely ill patients admitted to the intensive care unit (ICU) were not included in this analysis [52].

In 2014, two multicentre RCTs added new information to this field. In a non-inferiority RCT, GARIN et al. [53] compared treatment with $\beta$-lactam monotherapy with the $\beta$-lactam-macrolide combination. They included hospitalised patients with CAP (54\% of these patients had CURB-65 score $>2$ (confusion, urea $>7 \mathrm{mmol} \cdot \mathrm{L}^{-1}$, respiratory rate $\geqslant 30$ breaths $\mathrm{min}^{-1}$, blood pressure $<90 \mathrm{mmHg}$ (systolic) $\leqslant 60 \mathrm{mmHg}$ (diastolic), age $\geqslant 65$ years); patients with pneumonia severity index (PSI) class V were excluded). The primary end-point of clinical stabilisation on day 7 was less frequently reached under monotherapy. Again, particularly severely ill patients with a CURB score $\geqslant 2$ or a PSI class IV seemed to benefit from combination therapy. Notably, this also held true for patients with atypical pathogens, although a macrolide was added in any case of a positive Legionella urine antigen test in the $\beta$-lactam group. POsTMA et al. [54] reported the results of another non-inferiority RCT comparing $\beta$-lactam monotherapy with $\beta$-lactam-macrolide combination and with fluoroquinolone monotherapy. They included patients with CAP at baseline comparable to the study of GARIN et al. [53], but excluded patients requiring ICU admission. The primary end-point was 90-day mortality. $\beta$-lactam monotherapy was not inferior to combination therapy or fluoroquinolone treatment. Taken together, a potential immunomodulatory effect of macrolides may be irrelevant in non-severe CAP. RCTs performed in patients with severe CAP are lacking, and analysis of the inflammatory phenotype would be of great interest to address whether the experimental findings regarding immunomodulation by macrolides are relevant to the clinical setting.

Fluoroquinolones exhibiting a cyclopropyl moiety at position $\mathrm{N} 1$ of the quinolone core structure, i.e. ciprofloxacin or moxifloxacin may exert anti-inflammatory effects besides their well-established antimicrobial properties, as suggested by various in vitro studies [55-58]. However, in an experimental pneumonia model comparing moxifloxacin with the standard regimen of $\beta$-lactam therapy, no such effect could be detected [59]. Furthermore, combination therapy of meropenem with moxifloxacin had no benefit compared to meropenem monotherapy in sepsis, caused by pneumonia in the majority of patients [60]. Thus, a significant immunomodulatory effect of fluoroquinolones in pneumonia cannot be stated from currently available evidence.

\section{Improving pulmonary barrier function Adrenomedullin}

Adrenomedullin is an endogenous peptide expressed by different cell types of the vascular system including endothelial and vascular smooth muscle cells, and also by leukocytes, epithelial cells and cardiomyocytes. Adrenomedullin is derived from the precursor prepro-adrenomedullin and binds to the calcitonin receptor-like receptor (CRLR). In endothelial cells, receptor ligation by adrenomedullin causes intracellular accumulation of the second messenger cAMP, thereby activating various kinases such as protein kinase (PK) A, 
PKC and mitogen-activated protein kinases [61, 62]. The crucial role of adrenomedullin in protecting vascular barrier integrity was underscored by demonstrating that mice deficient in adrenomedullin, CRLR or other components of the adrenomedullin signalling pathway die prematurely due to hydrops fetalis [63-66]. Furthermore, inflammatory conditions such as sepsis or acute lung injury increased adrenomedullin expression [67-69], and the inflammatory response and organ damage in mice heterozygous for the adrenomedullin gene were aggravated upon LPS challenge [70]. Treatment with exogenous adrenomedullin improved pulmonary barrier dysfunction caused by different stimuli such as hydrogen peroxide, LPS or Staphylococcus aureus $\alpha$-toxin and was protective against ventilator-induced lung injury in mice with and without pneumonia [61, 71-74]. At least two major mechanisms underlie the barrier-protective effect of adrenomedullin: 1) reducing actin-myosin-based endothelial cell contraction [62] and 2) strengthening intercellular adherence junctions [75, 76]. Immunomodulatory properties have also been ascribed to adrenomedullin [77]; however we observed that the adrenomedullin-induced barrier protection was not necessarily associated with anti-inflammation [73, 74]. The impressive properties of adrenomedullin, independent of immunosuppressive effects, demonstrated in different complex experimental models suggest adrenomedullin to be a promising candidate for an adjuvant pharmacological approach to prevent lung injury in pneumonia.

\section{Angiopoietin/Tie2 system}

Angiopoietin (Ang)-1 and Ang-2 are ligands for the receptor tyrosine kinase Tie2, which is abundantly expressed by endothelial cells. Ang-1 and -2 are important regulators of angiogenesis, inflammation and vascular permeability [78, 79]. Binding of constitutively expressed Ang-1 to Tie2 induces endothelial quiescence, integrity and barrier stabilisation. In contrast, receptor binding of the functionally antagonistic ligand Ang-2, stored in endothelial Weibel-Palade bodies [80], results in endothelial destabilisation, inflammation and permeability [81, 82].

Ang-2 serum levels were increased in patients with sepsis compared to healthy volunteers and further increased in patients with sepsis-associated ARDS [83]. Furthermore, plasma Ang-2 levels had prognostic value for mortality in non-infection-related, but not in infection-related acute lung injury [84]. Besides being a marker of disease severity, a pathogenic role was ascribed to Ang- 2 in sepsis as Ang- $2^{+/-}$mice with reduced Ang-2 levels were protected against lung injury [85]. In support of this conclusion, Ziegler et al. [86] recently demonstrated that Ang-2 antibody treatment reduced permeability and mortality in mice upon LPS injection. Preclinical studies also demonstrated a protective anti-inflammatory effect of Ang- 1 . In experimental models of acute lung injury, transgenic Ang-1 overexpression or treatment led to reduced cytokine and adhesion molecule expression, polymorphonuclear infiltration and vascular leakage in the lung [87-90]. Although endothelial barrier-protective properties of Ang-1 have been demonstrated in several studies [87-89, 91-93], the methods of Ang-1 application, e.g. gene therapy or cell-based delivery, are far from translation into clinical therapies. In this context, the discovery of a short synthetic peptide (later termed vasculotide) that activates the Tie2 receptor and thereby completely inhibits binding of both ligands Ang-1 and Ang-2 [94] may represent an important milestone. In endotoxaemia and established abdominal sepsis in mice, vasculotide was already proven to have therapeutic potential by preventing/ counteracting vascular barrier dysfunction and reducing mortality [95, 96].

\section{Stem cell based approaches in lung injury}

Stem cells have the capacity for self-renewal and differentiation into many cell types and thereby contribute to the regeneration of injured organs [97]. In lung injury, stem cells were demonstrated to promote endothelial and epithelial repair by engrafting into tissue and interacting with neighbouring cells. This cell engraftment was suggested to be controlled by chemoattractants at the injury site as no exogenous stem cells were found in healthy lungs [98]. Furthermore, stem cells beneficially influence the host's immune response by reducing harmful inflammatory reactions and keeping its competence to fight pathogens [97]. The beneficial effects on immune responses and cellular functions described seem to be primarily based on paracrine mediators and mitochondria-containing microvesicles released by stem cells [99, 100].

Endothelial progenitor cells (EPCs) are a subtype of haematopoietic stem cells and exclusively differentiate into endothelial cells. EPCs can be isolated from different sources such as circulating mononuclear cells, bone marrow and cord blood. An increased number of circulating EPCs was detected in ARDS patients and correlated with improved survival [101]. However, in septic individuals endogenous EPCs showed reduced proliferative, adhesive, migratory and angiogenic capacities [102, 103]. Experimentally, two different approaches were performed to maintain the beneficial effects of EPCs. The first strategy was based on EPC transplantation from healthy donors. Using models of acute lung injury in rabbits and rats, EPC transplantation reduced lung oedema and attenuated hyaline membrane formation, probably due to re-endothelialisation of injured lung vasculature [98, 104]. In the second approach, autologous EPC transplantation was combined with application of the chemokine stromal cell-derived factor (SDF)- $1 \alpha$ 
supporting functionality of EPCs [105]. Indeed, exogenous EPCs and SDF- $1 \alpha$ synergistically improved pulmonary endothelial integrity and survival in murine polymicrobial sepsis [105]. EPC-based preventive or therapeutic approaches in ARDS seem promising, but further preclinical evaluation of efficacy and mechanisms of actions are necessary.

Currently, allogeneic bone marrow-derived human mesenchymal stem cells are being assessed as adjuvant therapy for the treatment of ARDS in a clinical phase I (NCT01775774) and multi-centre phase II trial (NCT02097641).

\section{Future perspectives}

The importance of inflammation and lung barrier failure in pneumonia-induced ARDS has been recognised for decades, and specific strategies to modulate pathophysiological mechanisms have been favourably tested in preclinical proof-of-concept models. Nevertheless, none of these strategies was clinically successful. To enhance translation efficacy, several aspects are worth considering. First, restoration of endothelial barrier function once the endothelium is severely injured may be a barely achievable goal. Therefore, pneumonia patients need to be stratified for high ARDS probability and treatment needs to be started early in a preventive manner, including resolution-enhancing strategies. Second, to relevantly reflect the patient with pneumonia, combinations of different preclinical models with sufficient complexity and accuracy regarding clinical situations need to be employed. Third, data from clinical registries, RCTs, patient “-omics" analyses, and preclinical mechanistic and therapeutic studies, to name a few, should be integrated in a systems-medicine approach by skilled information technology experts and biomathematicians in order to generate mathematical models. These models may enhance our understanding, create novel therapeutic perspectives and help define patient populations that may benefit from specific strategies.

\section{References}

1 Lode HM. Managing community-acquired pneumonia: a European perspective. Respir Med 2007; 101: $1864-1873$.

2 WHO. Pneumonia. Fact sheet N³31. www.who.int/mediacentre/factsheets/fs331/en/ Date last accessed: March 30, 2015. Date last updated: November, 2014.

3 Peiris JS, Yuen KY, Osterhaus AD, et al. The severe acute respiratory syndrome. N Engl J Med 2003; 349: 2431-2441.

4 Bautista E, Chotpitayasunondh T, Gao Z, et al. Clinical aspects of pandemic 2009 influenza A (H1N1) virus infection. N Engl J Med 2010; 362: 1708-1719.

5 Ewig S, Birkner N, Strauss R, et al. New perspectives on community-acquired pneumonia in 388406 patients. Results from a nationwide mandatory performance measurement programme in healthcare quality. Thorax 2009; 64: $1062-1069$.

6 Opitz B, van Laak V, Eitel J, et al. Innate immune recognition in infectious and noninfectious diseases of the lung. Am J Respir Crit Care Med 2010; 181: 1294-1309.

7 Müller-Redetzky HC, Suttorp N, Witzenrath M. Dynamics of pulmonary endothelial barrier function in acute inflammation: mechanisms and therapeutic perspectives. Cell Tissue Res 2014; 355: 657-673.

8 Ranieri VM, Rubenfeld GD, Thompson BT, et al. Acute respiratory distress syndrome: the Berlin Definition. JAMA 2012; 307: 2526-2533.

9 Verbrugge SJ, Lachmann B, Kesecioglu J. Lung protective ventilatory strategies in acute lung injury and acute respiratory distress syndrome: from experimental findings to clinical application. Clin Physiol Funct Imaging 2007; 27: 67-90.

10 The Acute Respiratory Distress Syndrome Network. Ventilation with lower tidal volumes as compared with traditional tidal volumes for acute lung injury and the acute respiratory distress syndrome. N Engl J Med 2000; 342: 1301-1308.

11 Briel M, Meade M, Mercat A, et al. Higher vs lower positive end-expiratory pressure in patients with acute lung injury and acute respiratory distress syndrome: systematic review and meta-analysis. JAMA 2010; 303: 865-873.

12 Talmor D, Sarge T, Malhotra A, et al. Mechanical ventilation guided by esophageal pressure in acute lung injury. N Engl J Med 2008; 359: 2095-2104.

13 Alhazzani W, Alshahrani M, Jaeschke R, et al. Neuromuscular blocking agents in acute respiratory distress syndrome: a systematic review and meta-analysis of randomized controlled trials. Crit Care 2013; 17 : R43.

14 Guérin C, Reignier J, Richard JC, et al. Prone positioning in severe acute respiratory distress syndrome. $N$ Engl $J$ Med 2013; 368: 2159-2168.

15 Papazian L, Forel JM, Gacouin A, et al. Neuromuscular blockers in early acute respiratory distress syndrome. N Engl J Med 2010; 363: 1107-1116.

16 Sud S, Friedrich JO, Taccone P, et al. Prone ventilation reduces mortality in patients with acute respiratory failure and severe hypoxemia: systematic review and meta-analysis. Intensive Care Med 2010; 36: 585-599.

17 Nie W, Zhang Y, Cheng J, et al. Corticosteroids in the treatment of community-acquired pneumonia in adults: a meta-analysis. PLoS One 2012; 7: e47926.

18 Confalonieri M, Urbino R, Potena A, et al. Hydrocortisone infusion for severe community-acquired pneumonia: a preliminary randomized study. Am J Respir Crit Care Med 2005; 171: 242-248.

19 Garcia-Vidal C, Calbo E, Pascual V, et al. Effects of systemic steroids in patients with severe community-acquired pneumonia. Eur Respir J 2007; 30: 951-956.

20 Tagami T, Matsui H, Horiguchi H, et al. Low-dose corticosteroid use and mortality in severe community-acquired pneumonia patients. Eur Respir J 2015; 45: 463-472. 

severe community-acquired pneumonia and high inflammatory response: a randomized clinical trial. JAMA 2015; 313: 677-686.

22 Blum CA, Nigro N, Briel $\mathrm{M}$, et al. Adjunct prednisone therapy for patients with community-acquired pneumonia: a multicentre, double-blind, randomised, placebo-controlled trial. Lancet 2015; 385: 1511-1518.

23 Ben DF, Yu XY, Ji GY, et al. TLR4 mediates lung injury and inflammation in intestinal ischemia-reperfusion. J Surg Res 2012; 174: 326-333.

24 Hilberath JN, Carlo T, Pfeffer MA, et al. Resolution of Toll-like receptor 4-mediated acute lung injury is linked to eicosanoids and suppressor of cytokine signaling 3. FASEB J 2011; 25: 1827-1835.

25 Imai Y, Kuba K, Neely GG, et al. Identification of oxidative stress and Toll-like receptor 4 signaling as a key pathway of acute lung injury. Cell 2008; 133: 235-249.

26 Tauseef M, Knezevic N, Chava KR, et al. TLR4 activation of TRPC6-dependent calcium signaling mediates endotoxin-induced lung vascular permeability and inflammation. J Exp Med 2012; 209: 1953-1968. Zanotti G, Casiraghi M, Abano JB, et al. Novel critical role of Toll-like receptor 4 in lung ischemia-reperfusion injury and edema. Am J Physiol Lung Cell Mol Physiol 2009; 297: L52-L63.

28 Mullarkey M, Rose JR, Bristol J, et al. Inhibition of endotoxin response by e5564, a novel Toll-like receptor 4-directed endotoxin antagonist. J Pharmacol Exp Ther 2003; 304: 1093-1102.

29 Lynn M, Rossignol DP, Wheeler JL, et al. Blocking of responses to endotoxin by E5564 in healthy volunteers with experimental endotoxemia. J Infect Dis 2003; 187: 631-639.

30 Tidswell M, Tillis W, Larosa SP, et al. Phase 2 trial of eritoran tetrasodium (E5564), a toll-like receptor 4 antagonist, in patients with severe sepsis. Crit Care Med 2010; 38: 72-83.

31 Opal SM, Laterre PF, Francois B, et al. Effect of eritoran, an antagonist of MD2-TLR4, on mortality in patients with severe sepsis: the ACCESS randomized trial. JAMA 2013; 309: 1154-1162.

32 Mastellos D, Morikis D, Isaacs SN, et al. Complement: structure, functions, evolution, and viral molecular mimicry. Immunol Res 2003; 27: 367-386.

33 Liu ZM, Zhu SM, Qin XJ, et al. Silencing of C5a receptor gene with siRNA for protection from Gram-negative bacterial lipopolysaccharide-induced vascular permeability. Mol Immunol 2010; 47: 1325-1333.

34 Müller-Redetzky HC, Kellermann U, Tschernig T, et al. Neutralizing the complement component C5a protects against lung injury and extrapulmonary organ injury in pneumococcal pneumonia induced sepsis. Am J Respir Crit Care Med 2014; 189: A1647.

35 Bhattacharya P, Budnick I, Singh M, et al. Dual role of GM-CSF as a pro-inflammatory and a regulatory cytokine: implications for immune therapy. J Interferon Cytokine Res 2015 [In press DOI: 10.1089/jir.2014.0149].

36 Meisel C, Schefold JC, Pschowski R, et al. Granulocyte-macrophage colony-stimulating factor to reverse sepsis-associated immunosuppression: a double-blind, randomized, placebo-controlled multicenter trial. Am J Respir Crit Care Med 2009; 180: 640-648.

Huang FF, Barnes PF, Feng Y, et al. GM-CSF in the lung protects against lethal influenza infection. Am J Respir Crit Care Med 2011; 184: 259-268.

38 Standiford LR, Standiford TJ, Newstead MJ, et al. TLR4-dependent GM-CSF protects against lung injury in Gram-negative bacterial pneumonia. Am J Physiol Lung Cell Mol Physiol 2012; 302: L447-L454.

39 Steinwede K, Tempelhof O, Bolte K, et al. Local delivery of GM-CSF protects mice from lethal pneumococcal pneumonia. J Immunol 2011; 187: 5346-5356.

40 Subramaniam R, Barnes PF, Fletcher K, et al. Protecting against post-influenza bacterial pneumonia by increasing phagocyte recruitment and ROS production. J Infect Dis 2014; 209: 1827-1836.

41 Paine R III, Standiford TJ, Dechert RE, et al. A randomized trial of recombinant human granulocyte-macrophage colony stimulating factor for patients with acute lung injury. Crit Care Med 2012; 40: 90-97.

42 Presneill JJ, Harris T, Stewart AG, et al. A randomized phase II trial of granulocyte-macrophage colony-stimulating factor therapy in severe sepsis with respiratory dysfunction. Am J Respir Crit Care Med 2002; 166: $138-143$.

43 Herold S, Hoegner K, Vadász I, et al. Inhaled granulocyte/macrophage colony-stimulating factor as treatment of pneumonia-associated acute respiratory distress syndrome. Am J Respir Crit Care Med 2014; 189: 609-611.

44 Anderson R, Steel HC, Cockeran R, et al. Clarithromycin alone and in combination with ceftriaxone inhibits the production of pneumolysin by both macrolide-susceptible and macrolide-resistant strains of Streptococcus pneumoniae. J Antimicrob Chemother 2007; 59: 224-229.

45 Kanoh S, Rubin BK. Mechanisms of action and clinical application of macrolides as immunomodulatory medications. Clin Microbiol Rev 2010; 23: 590-615.

46 Kudoh S, Azuma A, Yamamoto M, et al. Improvement of survival in patients with diffuse panbronchiolitis treated with low-dose erythromycin. Am J Respir Crit Care Med 1998; 157: 1829-1832.

47 Höffken G, Lorenz J, Kern W, et al. Epidemiologie, Diagnostik, antimikrobielle Therapie und Management von erwachsenen Patienten mit ambulant erworbenen unteren Atemwegsinfektionen sowie ambulant erworbener Pneumonie - Update 2009. [Epidemiology, diagnosis, antimicrobial therapy and management of community-acquired pneumonia and lower respiratory tract infections in adults. Guidelines of the Paul-Ehrlich-Society for Chemotherapy, the German Respiratory Society, the German Society for Infectiology and the Competence Network CAPNETZ Germany]. Pneumologie 2009; 63: e1-e68.

48 Mandell LA, Wunderink RG, Anzueto A, et al. Infectious Diseases Society of America/American Thoracic Society consensus guidelines on the management of community-acquired pneumonia in adults. Clin Infect Dis 2007; 44: Suppl. 2, S27-S72.

49 Woodhead M, Blasi F, Ewig S, et al. Guidelines for the management of adult lower respiratory tract infections summary. Clin Microbiol Infect 2011; 17: Suppl. 6, 1-24.

50 Martínez JA, Horcajada JP, Almela M, et al. Addition of a macrolide to a $\beta$-lactam-based empirical antibiotic regimen is associated with lower in-hospital mortality for patients with bacteremic pneumococcal pneumonia. Clin Infect Dis 2003; 36: 389-395.

51 Restrepo MI, Mortensen EM, Waterer GW, et al. Impact of macrolide therapy on mortality for patients with severe sepsis due to pneumonia. Eur Respir J 2009; 33: 153-159. 
Asadi L, Sligl WI, Eurich DT, et al. Macrolide-based regimens and mortality in hospitalized patients with community-acquired pneumonia: a systematic review and meta-analysis. Clin Infect Dis 2012; 55: 371-380.

Garin N, Genné D, Carballo $S$, et al. $\beta$-Lactam monotherapy vs $\beta$-lactam-macrolide combination treatment in moderately severe community-acquired pneumonia: a randomized noninferiority trial. JAMA Intern Med 2014; 174: 1894-1901.

Postma DF, van Werkhoven $\mathrm{CH}$, van Elden LJ, et al. Antibiotic treatment strategies for community-acquired pneumonia in adults. N Engl J Med 2015; 372: 1312-1323.

Araujo FG, Slifer TL, Remington JS. Effect of moxifloxacin on secretion of cytokines by human monocytes stimulated with lipopolysaccharide. Clin Microbiol Infect 2002; 8: 26-30.

Dalhoff A. Immunomodulatory activities of fluoroquinolones. Infection 2005; 33: Suppl 2, 55-70.

Donnarumma G, Paoletti I, Buommino E, et al. Anti-inflammatory effects of moxifloxacin and human $\beta$-defensin 2 association in human lung epithelial cell line (A549) stimulated with lipopolysaccharide. Peptides 2007; 28: 2286-2292.

Weiss T, Shalit I, Blau H, et al. Anti-inflammatory effects of moxifloxacin on activated human monocytic cells: inhibition of NF- $\mathrm{KB}$ and mitogen-activated protein kinase activation and of synthesis of proinflammatory cytokines. Antimicrob Agents Chemother 2004; 48: 1974-1982.

Müller-Redetzky HC, Wienhold SM, Berg J, et al. Moxifloxacin is not anti-inflammatory in experimental pneumococcal pneumonia. J Antimicrob Chemother 2015; 70: 830-840.

Brunkhorst FM, Oppert M, Marx G, et al. Effect of empirical treatment with moxifloxacin and meropenem vs meropenem on sepsis-related organ dysfunction in patients with severe sepsis: a randomized trial. JAMA 2012; 307: 2390-2399.

Hippenstiel S, Witzenrath M, Schmeck B, et al. Adrenomedullin reduces endothelial hyperpermeability. Circ Res 2002; 91: 618-625.

Temmesfeld-Wollbrück B, Hocke AC, Suttorp N, et al. Adrenomedullin and endothelial barrier function. Thromb Haemost 2007; 98: 944-951.

Czyzyk TA, Ning Y, Hsu MS, et al. Deletion of peptide amidation enzymatic activity leads to edema and embryonic lethality in the mouse. Dev Biol 2005; 287: 301-313. adrenomedullin gene. Proc Natl Acad Sci USA 2001; 98: 615-619.

Ichikawa-Shindo Y, Sakurai T, Kamiyoshi A, et al. The GPCR modulator protein RAMP2 is essential for angiogenesis and vascular integrity. J Clin Invest 2008; 118: 29-39.

Dackor RT, Fritz-Six K, Dunworth WP, et al. Hydrops fetalis, cardiovascular defects, and embryonic lethality in mice lacking the calcitonin receptor-like receptor gene. Mol Cell Biol 2006; 26: 2511-2518.

Agorreta J, Zulueta JJ, Montuenga LM, et al. Adrenomedullin expression in a rat model of acute lung injury induced by hypoxia and LPS. Am J Physiol Lung Cell Mol Physiol 2005; 288: L536-L545.

Cheung BM, Hwang IS, Li CY, et al. Increased adrenomedullin expression in lungs in endotoxaemia. J Endocrinol 2004; 181: 339-345.

Matheson PJ, Mays MP, Hurt RT, et al. Adrenomedullin is increased in the portal circulation during chronic sepsis in rats. Am J Surg 2003; 186: 519-525.

Dackor R, Caron K. Mice heterozygous for adrenomedullin exhibit a more extreme inflammatory response to endotoxin-induced septic shock. Peptides 2007; 28: 2164-2170.

Itoh T, Obata $\mathrm{H}$, Murakami S, et al. Adrenomedullin ameliorates lipopolysaccharide-induced acute lung injury in rats. Am J Physiol Lung Cell Mol Physiol 2007; 293: L446-L452.

Temmesfeld-Wollbrück B, Brell B, Dávid I, et al. Adrenomedullin reduces vascular hyperpermeability and improves survival in rat septic shock. Intensive Care Med 2007; 33: 703-710.

Thorax 2010; 65: 1077-1084.

Müller-Redetzky HC, Will D, Hellwig K, et al. Mechanical ventilation drives pneumococcal pneumonia into lung injury and sepsis in mice: protection by adrenomedullin. Crit Care 2014; 18: R73.

Hocke AC, Temmesfeld-Wollbrueck B, Schmeck B, et al. Perturbation of endothelial junction proteins by Staphylococcus aureus $\alpha$-toxin: inhibition of endothelial gap formation by adrenomedullin. Histochem Cell Biol 2006; 126: 305-316.

Honda M, Nakagawa S, Hayashi K, et al. Adrenomedullin improves the blood-brain barrier function through the expression of claudin-5. Cell Mol Neurobiol 2006; 26: 109-118.

Gonzalez-Rey E, Chorny A, Varela N, et al. Urocortin and adrenomedullin prevent lethal endotoxemia by down-regulating the inflammatory response. Am J Pathol 2006; 168: 1921-1930.

David S, Kümpers P, van Slyke P, et al. Mending leaky blood vessels: the angiopoietin-Tie2 pathway in sepsis. J Pharmacol Exp Ther 2013; 345: 2-6.

Eklund L, Saharinen P. Angiopoietin signaling in the vasculature. Exp Cell Res 2013; 319: 1271-1280.

Fiedler U, Scharpfenecker M, Koidl S, et al. The Tie-2 ligand angiopoietin-2 is stored in and rapidly released upon stimulation from endothelial cell Weibel-Palade bodies. Blood 2004; 103: 4150-4156.

Scharpfenecker M, Fiedler U, Reiss Y, et al. The Tie-2 ligand angiopoietin-2 destabilizes quiescent endothelium through an internal autocrine loop mechanism. J Cell Sci 2005; 118: 771-780.

Fiedler U, Reiss Y, Scharpfenecker M, et al. Angiopoietin-2 sensitizes endothelial cells to TNF- $\alpha$ and has a crucial role in the induction of inflammation. Nat Med 2006; 12: 235-239.

Parikh SM, Mammoto T, Schultz A, et al. Excess circulating angiopoietin-2 may contribute to pulmonary vascular leak in sepsis in humans. PLoS Med 2006; 3: e46.

Calfee CS, Gallagher D, Abbott J, et al. Plasma angiopoietin-2 in clinical acute lung injury: prognostic and pathogenetic significance. Crit Care Med 2012; 40: 1731-1737. in sepsis. Crit Care Med 2012; 40: 3034-3041.

Ziegler T, Horstkotte J, Schwab C, et al. Angiopoietin 2 mediates microvascular and hemodynamic alterations in sepsis. J Clin Invest 2013; 123: 3436-3445. 
Mammoto T, Parikh SM, Mammoto A, et al. Angiopoietin-1 requires p190 RhoGAP to protect against vascular leakage in vivo. J Biol Chem 2007; 282: 23910-23918.

Witzenbichler B, Westermann D, Knueppel S, et al. Protective role of angiopoietin-1 in endotoxic shock. Circulation 2005; 111: 97-105.

McCarter SD, Mei SH, Lai PF, et al. Cell-based angiopoietin-1 gene therapy for acute lung injury. Am J Respir Crit Care Med 2007; 175: 1014-1026.

$\mathrm{Xu} \mathrm{J,} \mathrm{Qu} \mathrm{J,} \mathrm{Cao} \mathrm{L,} \mathrm{et} \mathrm{al.} \mathrm{Mesenchymal} \mathrm{stem} \mathrm{cell-based} \mathrm{angiopoietin-1} \mathrm{gene} \mathrm{therapy} \mathrm{for} \mathrm{acute} \mathrm{lung} \mathrm{injury} \mathrm{induced}$ by lipopolysaccharide in mice. J Pathol 2008; 214: 472-481.

David S, Park JK, Meurs M, et al. Acute administration of recombinant angiopoietin-1 ameliorates multiple-organ dysfunction syndrome and improves survival in murine sepsis. Cytokine 2011; 55: 251-259.

Huang YQ, Sauthoff H, Herscovici P, et al. Angiopoietin-1 increases survival and reduces the development of lung edema induced by endotoxin administration in a murine model of acute lung injury. Crit Care Med 2008; 36: 262-267.

Mei SH, McCarter SD, Deng Y, et al. Prevention of LPS-induced acute lung injury in mice by mesenchymal stem cells overexpressing angiopoietin 1. PLoS Med 2007; 4: e269.

Tournaire R, Simon MP, le Noble F, et al. A short synthetic peptide inhibits signal transduction, migration and angiogenesis mediated by Tie2 receptor. EMBO Rep 2004; 5: 262-267.

Kumpers P, Gueler F, David S, et al. The synthetic Tie2 agonist peptide vasculotide protects against vascular leakage and reduces mortality in murine abdominal sepsis. Crit Care 2011; 15: R261.

David S, Ghosh CC, Kümpers P, et al. Effects of a synthetic PEG-ylated Tie-2 agonist peptide on endotoxemic lung injury and mortality. Am J Physiol Lung Cell Mol Physiol 2011; 300: L851-L862.

Cribbs SK, Matthay MA, Martin GS. Stem cells in sepsis and acute lung injury. Crit Care Med 2010; 38 : 2379-2385.

Mao M, Wang SN, Lv XJ, et al. Intravenous delivery of bone marrow-derived endothelial progenitor cells improves survival and attenuates lipopolysaccharide-induced lung injury in rats. Shock 2010; 34: 196-204.

Bhattacharya J, Matthay MA. Regulation and repair of the alveolar-capillary barrier in acute lung injury. Annu Rev Physiol 2013; 75: 593-615.

Islam MN, Das SR, Emin MT, et al. Mitochondrial transfer from bone-marrow-derived stromal cells to pulmonary alveoli protects against acute lung injury. Nat Med 2012; 18: 759-765.

Burnham EL, Taylor WR, Quyyumi AA, et al. Increased circulating endothelial progenitor cells are associated with survival in acute lung injury. Am J Respir Crit Care Med 2005; 172: 854-860.

Luo TH, Wang Y, Lu ZM, et al. The change and effect of endothelial progenitor cells in pig with multiple organ dysfunction syndromes. Crit Care 2009; 13: R118.

Patschan SA, Patschan D, Temme J, et al. Endothelial progenitor cells (EPC) in sepsis with acute renal dysfunction (ARD). Crit Care 2011; 15: R94.

Lam CF, Liu YC, Hsu JK, et al. Autologous transplantation of endothelial progenitor cells attenuates acute lung injury in rabbits. Anesthesiology 2008; 108: 392-401.

Fan H, Goodwin AJ, Chang E, et al. Endothelial progenitor cells and a stromal cell-derived factor-1 $\alpha$ analogue synergistically improve survival in sepsis. Am J Respir Crit Care Med 2014; 189: 1509-1519. 